\title{
INFLUÊNCIA DA ADUBAÇÃO NITROGENADA E POTÁSSICA NA EFICIÊNCIA DO USO DA ÁGUA E NA QUALIDADE DE FRUTOS DE MELÃ ${ }^{1}$
}

\author{
S. BUZETTI ${ }^{2}$; F.B.T. HERNANDEZ; M.E. SÅ ${ }^{2}$; M.A. SUZUKI ${ }^{3}$ \\ Departamento de Ciência do Solo e Engenharia Rural - FE/UNESP - C.P. 31, CEP:15378-000 - Ilha Solteira,SP.
}

\begin{abstract}
RESUMO: $O$ presente trabalho foi conduzido com o objetivo de se estudar 3 doses de $\mathrm{N}$ e 3 doses de $\mathrm{K}_{2} \mathrm{O}$, combinadas entre si e aplicadas em cobertura aos 15, 30 e 45 dias após a emergência das plântulas, na eficiência do uso da água e na qualidade de frutos de melão. Utilizou-se um Podzólico Vermelho Escuro, eutrófico, textura média/argilosa, do município de Ilha Solteira(SP). O experimento foi implantado no ano de 1991 fazendo-se uso dos cultivares Valenciano Amarelo e Eldorado 300, em espaçamento de $2,0 \mathrm{~m}$ entre limhas e $0,75 \mathrm{~m}$ entre covas. A cultura foi conduzida sem capação e desbrota e os tratamentos fitossanitários procedidos de acordo com a necessidade. Pelos resultados obtidos verificou-se que o $\mathrm{N}$ ou o $\mathrm{K}_{2} \mathrm{O}$ influenciaram alguns parâmetros no cultivar Eldorado 300: peso da casca, peso de sementes com mucilagem e acidez titulável, além do rendimento de polpa no cultivar Valenciano Amarelo.

Descritores: melão, nitrogênio, potássio, qualidade de frutos, eficiência do uso da água.
\end{abstract}

\section{INFLUENCE OF NITROGEN AND POTASSIUM FERTILIZATION ON WATER USE EFFICIENCY AND FRUIT QUALITY FOR MELON CROP}

SUMMARY: The present work was developed with the objective of studying 3 combined doses of $\mathrm{N}$ and $\mathrm{K}_{2} \mathrm{O}$, applied as cover dressings within 15, 30 and 45 days after seedling emergence, in the water efficience use and fruit quality of muskmelons grown on a Dark Red Podzolic soil. The experiment was carried in Ilha Solteira, São Paulo State, Brazil. The experiment was carried out in 1991 with the Valenciano Amarelo and Eldorado 300 cultivars, in a $2.0 \times 0.75 \mathrm{~m}$ spacing. The results showed that $\mathrm{N}$ and $\mathrm{K}_{2} \mathrm{O}$ influenced some parameters of the Eldorado 300 cultivar: peel weight, seed weight and acidity; pulp yield in Valenciano Amarelo cultivar.

Key Words: muskmelon, nitrogen, potassium, fruit quality, water use eficiency.

\section{INTRODUÇÃO}

Segundo NAGAI (1987) o volume comercializado do melão a nível nacional ultrapassa 60.000 toneladas, das quais, mais de $60 \%$ são consumidas em São Paulo e $20 \%$ exportada. Assim, o melão passou de artigo importado para artigo de exportação. Sendo artigo de exportação, o aroma, sabor e o visual destes frutos são fatores determinantes da qualidade dos mesmos $\mathrm{e}$, portanto, definitivos para uma boa comercialização. A adubação passa então a ter uma importância maior na cultura, tendo em vista os reais efeitos na qualidade.
VIEIRA (1984) cita que a qualidade dos melões está altamente correlacionada como o conteúdo de açúcares, por isso um fruto realmente bom deve apresentar um sabor característico, que é função dos compostos orgânicos, produzidos durante o amadurecimento. Alguns destes compostos foram identificados e muitos deles são álcoois e ésteres de ácidos.

Para FILGUEIRA (1981) o clima afeta muito a qualidade dos frutos e a produtividade da planta, exigindo altas temperaturas e baixa umidade do ar para que se obtenha frutos de melhor sabor, mais consistentes e de melhor durabilidade. A temperatura ideal para o desenvolvimento do

\footnotetext{
'Trabalho desenvolvido com apoio financeiro da FAPESP e CNPq.

${ }^{2}$ Bolsista do CNPq.

${ }^{3}$ Bolsista da FAPESP.
}

Sci. agric., Piracicaba, 50(2):419-426, out./dez., 1993 
"Valenciano" está compreendida entre 25 e $32^{\circ} \mathrm{C}$. Em temperatura atmosférica abaixo de $15^{\circ} \mathrm{C}$ e temperatura do solo inferior a $18^{\circ} \mathrm{C}$, pode ocorrer a paralização do seu desenvolvimento, o que demonstra ser a região ecológica de Ilha Solteira excelente para o seu cultivo.

MENGEL \& KIRKBY (1987), relatam que a síntese de citocininas é diminuída com a nutrição inadequada de nitrogênio. Como esses fitormônios promovem um vigoroso crescimento $e$ a retenção da planta em um estágio juvenil por mais tempo, a deficiência de citocinina pode ter bom resultado na senescência.

ERMLAND JR. (1986), relata que as condições de cultivo do meloeiro é um dos fatores que tem grande influência na qualidade dos frutos. A coloração e as características organolépticas são dependentes da adubação, do solo, do clima e da disponibilidade hídrica, da mesma forma como o tamanho dos frutos está amplamente relacionado com a produtividade da planta, dada a limitação da área foliar por fruto, o que melhora a qualidade dos frutos e conseqüentemente seu valor comercial, como também sua resistência a transporte e armazenamento. A eficiência do uso da água (e.u.a.) e a resistência à seca são frequentemente tratados como sinônimos, embora eles normalmente não estejam relacionados (HSIAO, 1973; BEGG \& TURNER, 1976). A e.u.a. refere-se a um parâmetro de rendimento total da colheita por unidade de água utilizada e o maior objetivo das pesquisas nesta área está em conseguir altos valores da e.u.a., mantendo-se altas produtividades. No entanto, a ênfase dada à resistência à seca é freqüentemente relacionada à sobrevivência da planta durante períodos de déficit hídrico, resultante do baixo fornecimento de água e alta radiação, temperatura e demanda evaporativa da atmosfera (HERNANDEZ, 1991). De acordo com este autor, tanto a produtividade biológica ou a de frutos e a quantidade de água evapotranspirada, são dependentes do balanço de energia e a e.u.a, por sua vez, é dependente da distribuição de energia dentro da cultura.

Pelo acima exposto, procurou-se, com o presente trabalho, estudar os efeitos das doses de $\mathrm{N}$ e de $\mathrm{K}_{2} \mathrm{O}$ na eficiência do uso da água e na qualidade de frutos de melão.

\section{MATERIAL E METODOS}

Utilizou-se de um Podzólico Vermelho Escuro, eutrófico, abrúptico, A chernozêmico, textura média/argilosa, com as seguintes características químicas: $\mathrm{pH}$ em CaCl2 $=5,5$, M.O. $(\%)=2,10$, P resina $\left(\mu \mathrm{g} / \mathrm{cm}^{3}\right)=28, \mathrm{~K}=$ $0,5, \mathrm{Ca}=2,9, \mathrm{Mg}=1,2, \mathrm{H}+\mathrm{Al}=1,5, \mathrm{~S}=$ $4,6, \mathrm{~T}=6,1 \mathrm{meq} / 100 \mathrm{~cm} \mathrm{e} \mathrm{V}=75 \%$, pertencente ao município de llha Solteira-SP.

A cultura utilizada foi a do melão e os cultivares o Valenciano Amarelo e o Eldorado 300 A semeadura foi efetuada em agosto de 1991, manualmente, num espaçamento de $2,0 \mathrm{~m}$ entre linhas e $0,75 \mathrm{~m}$ entre covas. Semeou-se 4 sementes em cada cova, desbastando-se para 2 plantas, logo após a emergência das primeiras folhas verdadeiras. No estágio de 4 folhas definitivas realizou-se outro desbaste deixando-se 1 planta por cova.

A adubação de plantio foi fixa para todos os tratamentos constando de $300 \mathrm{~g} /$ cova da fórmula 4-30-10 e as coberturas, que constituíram os tratamentos, de 3 doses de $\mathrm{N}$ e 3 doses de $\mathrm{K}_{2} \mathrm{O}$ : 2,5; 5,0 e 10,0g/cova, representadas pelos níveis 1 , 2 e 3, aplicadas aos 15,30 e 45 dias após a emergência das plântulas, em um delineamento em blocos ao acaso com 4 repetições.

A condução da cultura se deu sem capação e sem desbrotas, utilizando-se de um sistema de irrigação por gotejamento, repondo a evapotranspiração da cultura, calculada com basc na evaporação do Tanque Classe $A$, segundo metodologia sugerida por DOORENBOS \& PRUITT (1976), sendo que cada planta contou com um gotejador. As parcelas estavam constituídas por 3 linhas e 10 plantas por linha, amostrando-se as plantas da linha central omitindo-se uma planta de cada extremidade. A colheita foi iniciada $\mathrm{cm}$ 24/10/91, para ambos os cultivares e terminada em 14 e 22/11/91 para os cultivares Valenciano Amarelo e Eldorado 300, respectivamente.

Após a colheita do dia 31/10/91, foram realizadas análises laboratorias com a finalidade de se obter os teores correspondentes de sólidos solúveis, acidez titulável e o cálculo do índice de maturação (relação entre sólidos solúveis e a acidez titulável).

Os teores de sólidos solúveis (brix) foram obtidos através de leitura em refratômetro com os frutos completamente maduros. A acidez titulável foi determinada utilizando-se uma alíquota de $10 \mathrm{~g}$ de polpa, a qual se adicionou $20 \mathrm{ml}$ de água destilada e 3 gotas de fenolftaleína $1 \%$. A seguir foi feita a titulação até o ponto de viragem com $\mathrm{NaOH}(0,10 \mathrm{~N})$, previamente padronizado, segundo metodologia proposta pelo INSTITUTO ADOLFO 
LUTZ (1985). As análises foram realizadas no dia seguinte à colheita.

O rendimento de polpa foi determinado através da relação entre o peso de polpa e o peso total do fruto. O peso de polpa foi obtido por diferença entre o peso total e a soma dos pesos da casca e das sementes mais a mucilagem.

O crescimento da cultura foi dividido em estádios fenológicos de acordo com observações de caráter morfológico. Esses estádios foram assim distribuídos:

- Emergência de plantas ou estádio inicial: da semeadura até a emergência de $50 \%$ mais uma planta;

- Vegetativo: do final do ciclo anterior até 50\% mais uma planta apresentarem flores;

- Florescimento ou reprodutivo: do final do ciclo anterior até que $50 \%$ mais uma planta apresentarem frutos;

- Frutificação: do final do ciclo anterior até o início da colheita $\mathrm{e}$

- Colheita: do final do ciclo anterior até a última colheita.

De acordo com DOORENBOS \& KASSAM (1988) a eficiência do uso da água pode ser determinada tanto para a produtividade biológica, como para a produtividade de frutos. Neste caso foi determinada para a produção final de frutos, feita através da relação entre o peso total de frutos ( $\mathrm{kg} / \mathrm{ha}$ ) e o consumo de água (litros) durante o ciclo da cultura, sendo o resultado transformado $\mathrm{em} \mathrm{g} / \mathrm{m}^{2} / \mathrm{mm}$.

\section{RESULTADOS E DISCUSSAO}

Na TABELA 1 encontram-se os valores de $F$, médias gerais e coeficientes de variação, referentes ao peso de casca, peso de sementes com mucilagem, rendimento de polpa, brix, acidez titulável e índice de maturação, para os dois cultivares testados. Verifica-se que para $o$ parâmetro peso de casca só houve efeito no Eldorado 300. Neste caso, como a interação N x K foi significativa, procedeu-se ao desdobramento das doses de $\mathrm{N}$ dentro de cada dose de potássio. Observou-se que os dados (peso de casca) se ajustaram a uma função linear crescente, ou seja, à medida em que se aumentou as doses de $\mathrm{N}$ houve um aumento no parâmetro avaliado, na condição de $2,5 \mathrm{~g} /$ planta de $\mathrm{K}_{2} \mathrm{O}$.

Entretanto, quando se testou doses de $\mathrm{N}$ dentro das doses de 5 e $10 \mathrm{~g} /$ planta de $\mathrm{K} 2 \mathrm{O}$, houve diminuição linear no peso de casca. No caso em pauta deverá ser verificada a influência deste parâmetro na qualidade do fruto, assim como no armazenamento, para se verificar se é compensatório a utilização de doses maiores ou menores de nitrogênio e de potássio.

Com relação ao peso de sementes com mucilagem, para o cultivar Valenciano Amarelo, houve efeito linear crescente das doses de potássio, independente da dose de nitrogenio, ou seja, houve aumento no peso das sementes com o aumento das doses aplicadas de potássio. Para o Eldorado 300 houve dependência entre os dois nutrientes testados, sendo que o peso das sementes se ajustou a uma função linear crescente, em relação às doses de $\mathrm{N}$ dentro da dose $2.5 \mathrm{~g}$ /planta de $\mathrm{K} 2 \mathrm{O}$ e, a uma função quadrática, com ponto de máximo de $7,29 \mathrm{~g}$ de $\mathrm{N}$ por planta, quando se testou $5 \mathrm{~g}$ /planta de $\mathrm{K}_{2} \mathrm{O}$. Na dose superior de $\mathrm{K}_{2} \mathrm{O}$ não houve ajuste a nenhuma função matemática. Para este parâmetro - que deve ser levado em consideração seria verificar a viabilidade de se comercializar as sementes, pois neste caso os frutos são descartados.

Para o rendimento de polpa, no cultivar Valenciano Amarelo, verificou-se um efeito quadrático das doses de $\mathrm{N}$, com o ponto de máximo sendo alcançado com a dose de $6,44 \mathrm{~g}$ de $\mathrm{N} /$ planta e, um efeito linear crescente para as doses de $\mathrm{K}$, ou seja, à medida que se aumentou a dose de potássio houve aumento no rendimento de polpa. Por outro lado, o mesmo não ocorreu com o Eldorado 300 , onde os dados de rendimento não se ajustaram a nenhuma função matemática $\mathrm{em}$ relação às doses aplicadas. Para o brix e acidez titulável não houve ajuste, assim como para o índice de maturação, em relação ao Valenciano Amarelo. Para o Eldorado 300 os dados de índice de maturação se ajustaram a uma função linear crescente, em relação às doses de $\mathrm{N}$. Neste caso seria interessante aumentar a dose de $\mathrm{N}$ para se aumentar tal índice, com isso teríamos frutos no mercado com uma certa antecedência.

$\mathrm{Na}$ TABELA 2 se encontram os resultados médios, para os diferentes tratamentos, em relação às características qualitativas, onde se verifica dados numéricos inferiores, para o cultivar Eldorado 300, em relação ao Valenciano Amarelo, exceção feita ao índice de maturação. 
TABELA 1 - Valores de F, médias gerais e coeficientes de variação, referentes ao peso da casca, peso de sementes com mucilagem, rendimento de polpa, brix, acidez titulável e índice de maturação, de frutos de melão (cultivares Valenciano Amarelo e Eldorado 300).

\begin{tabular}{|c|c|c|c|c|c|c|}
\hline \multirow{2}{*}{$\begin{array}{c}\text { Causas de } \\
\text { Variação }\end{array}$} & \multicolumn{2}{|c|}{ peso de casca } & \multicolumn{2}{|c|}{ peso de sementes } & \multicolumn{2}{|c|}{ rendimento } \\
\hline & 1 & 2 & 1 & 2 & 1 & 2 \\
\hline $\mathrm{N}$ & 2,06 & 1,35 & 0,57 & 0,59 & $6,64 * *$ & 0,63 \\
\hline RL & 1,50 & 2,26 & 0,49 & 0,59 & 0,01 & 0,73 \\
\hline RQ & 2,62 & 0,43 & 0,65 & 1,10 & $13,29 * *^{9}$ & 0,53 \\
\hline $\mathrm{K}$ & 0,24 & $4,97 *$ & $6,61 * *$ & 1,73 & 4,53 & 1,23 \\
\hline $\mathrm{RL}$ & 0,35 & 2,54 & $13,20 * * 6$ & 2,49 & $7,54 * 10$ & 0,46 \\
\hline $\mathrm{RQ}$ & 0,12 & $7,41 *$ & 0,02 & 0,97 & 1,52 & 2,00 \\
\hline $\mathrm{N} * \mathrm{~K}$ & 0,74 & $4,21 *$ & 2,58 & $5,89 * *$ & 2,67 & 1,76 \\
\hline $\mathrm{N}$ d. $\mathrm{K} 2,5 \mathrm{RL}$ & & $4,57 *^{3}$ & & $11,58 * * 7$ & & \\
\hline$R Q$ & & 2,96 & & 0,07 & & \\
\hline N d. K5 RL & & $4,49 *^{4}$ & & $5,82 * *$ & & \\
\hline $\mathrm{RQ}$ & & 0,04 & & $6,76 * * 8$ & & \\
\hline $\mathrm{N}$ d. K10 RL & & $6,90 * 5$ & & 0,23 & & \\
\hline $\mathrm{RQ}$ & & 0,59 & & 0,27 & & \\
\hline Média geral & 227,77 & 256,98 & 99,18 & 112,17 & 74,76 & 77,30 \\
\hline C.V. (\%) & 23,32 & 18,72 & 13,30 & 12,70 & 4,35 & 4,78 \\
\hline Causas de & & & acide & lável & índice de & uração \\
\hline Variação & 1 & 2 & 1 & 2 & 1 & 2 \\
\hline $\mathrm{N}$ & 1,09 & 0,50 & 0,66 & 3,23 & 0,13 & 1,73 \\
\hline RL & 2,16 & 0,99 & 1,08 & $6,45^{* 11}$ & 0,11 & 3,45 \\
\hline RQ & 0,02 & 0,01 & 0,24 & 0,01 & 0,15 & 0,53 \\
\hline $\mathrm{K}$ & 0,66 & 0,67 & 0,93 & 1,15 & 0,59 & 2,60 \\
\hline RL & 1,11 & 1,31 & 1,17 & 0,16 & 0,21 & 1,61 \\
\hline $\mathrm{RQ}$ & 0,20 & 0,04 & 0,68 & 0,68 & 0,97 & 3,58 \\
\hline $\mathrm{N} * \mathrm{~K}$ & 0,48 & 1,57 & 0,59 & 0,93 & 1,51 & 1,47 \\
\hline Média geral & 9,16 & 9,61 & 5,48 & 6,37 & 1,72 & 1,54 \\
\hline C.V. (\%) & 11,05 & 9,15 & 18,04 & 14,39 & 8,74 & 13,19 \\
\hline
\end{tabular}

1) Valenciano Amarelo; 2) Eldorado 300 ; 3) $\mathrm{Y}=207,9875+9,5236 \mathrm{X}$; 4) $\mathrm{Y}=278,3000-9,4357 \mathrm{X}$;

5) $\mathrm{Y}=352,4000-11,7000 \mathrm{X}$; 6) $\mathrm{Y}=84,2333+2,5619 \mathrm{X}$; 7) $\mathrm{Y}=79,8125+4,4893 \mathrm{X}$; 8) $\mathrm{Y}=190,7166-$ $26,9350 X+1,8473 X^{2}$; 9) $\left.Y=64,0472+4,3983 X-0,3416 X^{2} ; 10\right) Y=71,9750+0,4776 X$. 
TABELA 2 - Valores médios obtidos para algumas características qualitativas de frutos de melão.

\begin{tabular}{lcccccc}
\hline \hline & \multicolumn{2}{c}{ peso $(\mathrm{g})$} & rendimento & Brix & acidez & índice \\
\cline { 2 - 4 } Tratamento & casca & semente & $\begin{array}{c}\text { de polpa }(\%) \\
\text { titulável }\end{array}$ & maturação* \\
\hline & & & VALENCIANO AMARELO & & \\
N1K1 & 219,9 & 97,0 & 71,7 & 8,6 & 6,0 & 1,4 \\
N1K2 & 229,1 & 91,8 & 72,4 & 9,0 & 5,3 & 1,7 \\
N1K3 & 239,4 & 99,0 & 74,6 & 9,0 & 4,7 & 1,9 \\
N2K1 & 211,6 & 79,2 & 76,7 & 9,4 & 5,3 & 1,8 \\
N2K2 & 196,9 & 103,6 & 79,5 & 9,5 & 5,3 & 1,8 \\
N2K3 & 206,5 & 120,9 & 76,3 & 8,6 & 5,3 & 1,6 \\
N3K1 & 260,2 & 94,8 & 69,3 & 9,8 & 6,0 & 1,6 \\
N3K2 & 274,3 & 97,2 & 74,0 & 9,5 & 5,3 & 1,8 \\
N3K3 & 212,2 & 109,3 & 78,4 & 9,1 & 5,8 & 1,6 \\
\hline & & & ELDORADO 300 & & 1,3 \\
N1K1 & 253,9 & 90,0 & 71,1 & 9,5 & 6,1 & 1,6 \\
N1K2 & 257,2 & 134,9 & 71,9 & 8,6 & 5,8 & 1,5 \\
N1K3 & 313,3 & 116,2 & 72,0 & 9,4 & 5,5 & 1,7 \\
N2K1 & 222,5 & 103,8 & 73,9 & 9,6 & 6,6 & 1,5 \\
N2K2 & 227,4 & 102,2 & 73,1 & 9,9 & 6,7 & 1,5 \\
N2K3 & 308,8 & 119,6 & 71,6 & 9,8 & 6,9 & 1,4 \\
N3K1 & 314,2 & 124,2 & 68,2 & 9,8 & 7,2 & 1,4 \\
N3K2 & 210,2 & 106,1 & 74,6 & 9,8 & 6,5 & 1,5 \\
N3K3 & 230,5 & 112,5 & 73,0 & 9,0 & 5,5 & 1,6 \\
\hline \hline
\end{tabular}

* Ratio.

Na TABELA 3 consta o número médio de dias para cada estádio fenológico da cultura. Por esta tabela verifica-se que o cultivar Eldorado 300 apresentou um ciclo maior que o cultivar Valenciano Amarelo. Para o primeiro cultivar foram efetuadas 5 colheitas, enquanto que para o segundo foram efetuadas 4 colheitas.

BELFORT et al. (1988) relatam que em experimento com o cultivar Valenciano Amarelo, este apresentou um ciclo fenológico de 75 dias, portanto, um ciclo semelhante ao alcançado no presente ensaio, mesmo considerando que as condições de clima apresentam-se diferentes nestes ensaios, e considerando o tempo de emergência o ciclo daquele experimento foi de 82 dias.

Com relação ao consumo de água pela cultura (Figura 1) este foi da ordem de 2.093,41 e $1.770,76 \mathrm{~m}^{2} / \mathrm{ha}$, representado por $133,24 \mathrm{e} 112,54$ horas de bombeamento, respectivamente para os cultivares Eldorado 300 e Valenciano Amarelo.

A eficiência do uso da água e a produtividade da cultura, para os tratamentos aplicados, estão apresentadas na TABELA 4, onde verifica-se que para o cultivar Valenciano 
TABELA 3 - Datas de ocorrência e duração média (dias) de cada estádio fenológico da cultura do meloeiro cultivada em Ilha Solteira (SP).

\begin{tabular}{lcccc}
\hline & \multicolumn{2}{c}{ Valenciano Amarelo } & \multicolumn{2}{c}{ Eldorado 300} \\
Estádio & Data & Período (dias) & Data & Período (dias) \\
\hline Emergência & $28 / 08 / 91$ & 7 & $28 / 08 / 91$ & 7 \\
Vegetativo & $23 / 09 / 91$ & 26 & $22 / 09 / 91$ & 25 \\
Florescimento & $02 / 10 / 91$ & 9 & $01 / 10 / 91$ & 9 \\
Frutificação & $24 / 10 / 91$ & 22 & $24 / 10 / 91$ & 23 \\
Colheita & $14 / 11 / 91$ & 21 & $22 / 11 / 91$ & 29 \\
TOTAL & - & 85 & - & 93 \\
\hline \hline
\end{tabular}

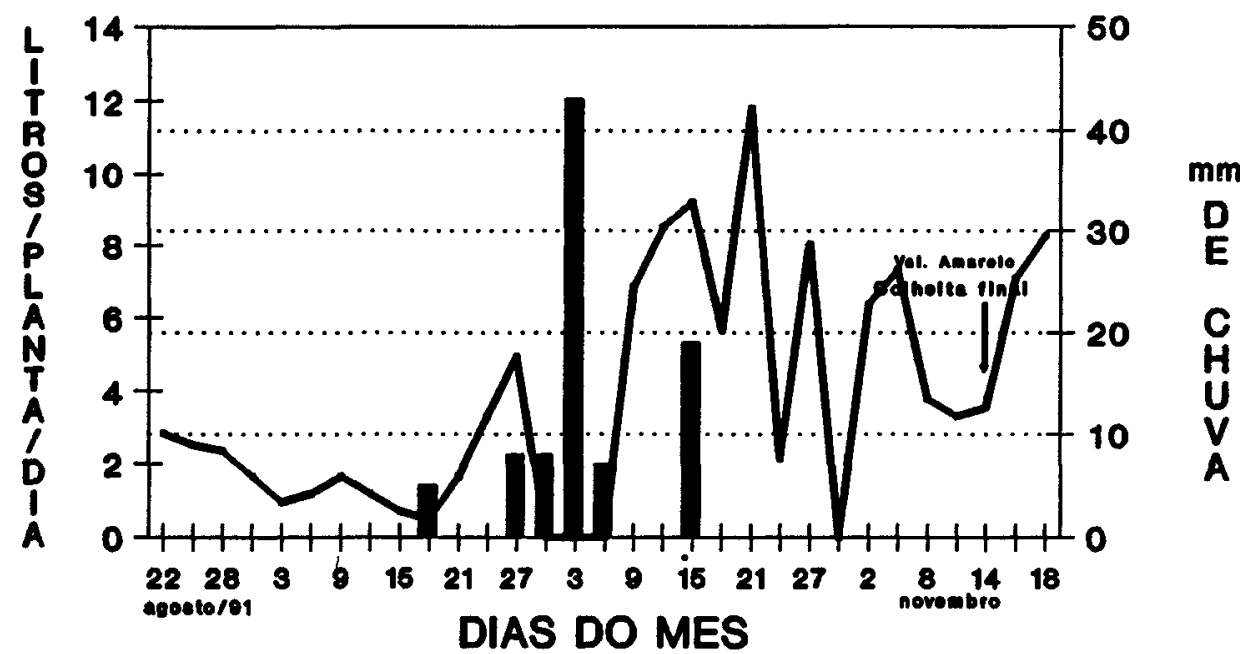

Figura 1 - Irrigação e precipitação diária ocorrida na cultura do meloeiro cultivada em Ilha Solteira,SP.

Amarelo, os tratamentos designados por N1K1 eN1K2 foram os que apresentaram as maiores $e$ menores médias da e.u.a., respectivamente $11,5 \mathrm{e}$ $8,8 \mathrm{~g} / \mathrm{m}^{2} / \mathrm{mm}$.

Já para o cultivar Eldorado 300 as maiores e menores médias ficaram para os tratamentos N1K2 e N2K3, respectivamente 12,2 e 7,4 $\mathrm{g} / \mathrm{m}^{2} / \mathrm{mm}$. Se forem comparados os dois cultivares verifica-se que a média para todos os tratamentos apresentam praticamente a mesma magnitude, ou seja, 10,7 e $10,9 \mathrm{~g} / \mathrm{m}^{2} / \mathrm{mm}$, para os cultivares Valenciano Amarelo e Eldorado 300, respectivamente. Ressalta-se que os dados de produção não se ajustaram a nenhuma função matemática. 
TABELA 4 - Resultados obtidos para a eficiência do uso da água (e.u.a.) para dois cultivares de melão.

\begin{tabular}{ccccc}
\hline \hline & $\begin{array}{c}\text { produtividade } \\
(\mathrm{kg} / \mathrm{ha})\end{array}$ & $\begin{array}{c}\text { e.u.a. } \\
\left(\mathrm{g} / \mathrm{m}^{2} / \mathrm{mm}\right)\end{array}$ & $\begin{array}{c}\text { produtividade } \\
(\mathrm{kg} / \mathrm{ha})\end{array}$ & $\begin{array}{c}\text { e.u.a. } \\
\left(\mathrm{g} / \mathrm{m}^{2} / \mathrm{mm}\right)\end{array}$ \\
\cline { 2 - 5 } & \multicolumn{2}{c}{ Valenciano Amarelo } & \multicolumn{2}{c}{ Eldorado 300} \\
\hline N1K1 & 20.367 & 11,5 & 24.557 & 11,7 \\
N1K2 & 15.597 & 8,8 & 25.505 & 12,2 \\
N1K3 & 18.503 & 10,4 & 23.650 & 11,3 \\
N2K1 & 17.521 & 9,9 & 21.841 & 10,4 \\
N2K2 & 17.659 & 10,0 & 24.144 & 11,5 \\
N2K3 & 22.946 & 13,0 & 16.031 & 7,4 \\
N3K1 & 19.960 & 11,3 & 21.098 & 10,1 \\
N3K2 & 19.283 & 10,9 & 22.850 & 10,9 \\
N3K3 & 18.358 & 10,4 & 25.761 & 12,3 \\
\hline \hline
\end{tabular}

Os valores obtidos em cada tratamento traduzem a importância do manejo correto da cultura para que se tenha uma máxima produção por unidade de água aplicada. Convém lembrar que cm muitos locais a quantidade de água oferecida aos irrigantes é escassa e desse modo torna-se limitante para a cultura a aplicação de água corretamente. Nestes casos uma perfeita combinação entre as adubações e as irrigações torna-se extremamente desejável.

\section{CONCLUSÕES}

Tendo como base as informações levantadas através da presente pesquisa, foram obtidas as seguintes conclusões:

- Com relação ao ciclo da cultura verificou-se que - cultivar Eldorado 300 apresentou um ciclo fenolbgico maior que o Valenciano Amarelo (93 contra 85 dias). Esta diferença se deu principalmente devido ao alongamento da colheita, onde o cultivar Eldorado 300 proporcionou 5 colheitas de frutos, em detrimento de 4 colheitas feitas no cultivar Valenciano Amarelo;

- As doses de N e K2O a serem aplicadas vão depender da finalidade da produção, qual seja, comercialização de sementes, comercialização de fruto imediatamente após a colheita ou que sofrerá armazenamento e tipo de consumidor;

- A adubação influenciou o aproveitamento da água pelos cultivares estudados.

\section{REFERENCIAS BIBLIOGRAFICAS}

BEGG, J.E., TURNER, N.C. Crop water deficits. Advances in Agronony, New York, v.43, p.65-217, 1976.

BELFORT, C.C.; HAAG, H.P.; CARMELLO, Q.A.C.; SANTOS, J.W.C. Acumulação de matéria seca e recrutamento de macronutrientes pelo melão (Cucumis melo L. cv. Valenciano Amarelo CAC) cultivado em Latossolo Vermelho Amarelo em Presidente Venceslau,SP. In: HAAG, H.P.; MINAMI, K., (Ed.) Nutriçăo mineral em hortaliças. 2.ed. Campinas: Fundação Cargill, 1988. p.293-349.

DOORENBOS, J.; KASSAM, A.H. Efectos del agua sobre el rendimiento de los cultivos. Roma: FAO, 1988. 212p. (Boletim, 33).

DOORENBOS, J.; PRUITT, W.O. Las necesidades de agua de los cultivos. Roma, FAO, 1976. 194p. (Boletim, 24). 
ERMLAND JR., F.K.V. Efeito do cultivo em casa de vegetação com cobertura de filme de polietileno, sobre a qualidade tecnologica e conservação pos colheita de melão (Cucumis melo L.) cv. "Valenciano Amarelo CAC", com uso da irrigação por jato-pulsante. Jaboticabal, UNESP/FCAV, 1986. 55p.

FILGUEIRA, F.A.R. Manual de olericultura: cultura e comercialização de hortaliças. 2.ed, São Paulo: Editora Ceres, 1981. v.1, 338p.

HERNANDEZ, F.B.T. Determinação do consumo de água na cultura do trigo (Triticum aestivum L.) na regiāo de Jaboticabal-SP. Jaboticabal, 1991. 77p. Dissertação (Mestrado) - Faculdade de Ciências Agrárias e Veterinárias, Universidade Estadual Paulista Prof. Julio de Mesquita Filho.

HSIAO, T.C. Plant response to water stress. Annual Review of Plant Physiology, Palo Alto, v.24, p.519-570, 1973.

INSTITUTO ADOLFO LUTZ. Normas analíticas do Instituto Adolfo Lutz: métodos químicos e físicos para análise de alimentos. 3.ed., São Paulo: Secretaria da Saúde, 1985. v.1, 533p.
MENGEL, K.; KIRKBY, E.A. Principle of plant nutrition. 4.ed. Switzerland: Internacional Potash Institute, 1987.699p.

NAGAI, H. Melão (Cucumis melo L.). In: PEDRO JR., M.J.; BULISANI, E.A.; POMMER, C.V.; PASSOS, F.A.; GODOY, I.J.; ARANHA, C. (Ed.). Instruçöes Agrícolas para o Estado de São Paulo: melão. Campinas: Instituto Agronômico, 1987. p.145. (Boletim, 200).

VIEIRA, G. Índices de maturação para melão (Cucumis melo L.). In: HEREDIA, M.C.V. de; CASALI, V.W.D. (Coord.). Seminário de Olericultura. Viçosa: UFV, 1984. v.10, p.48-67.

Enviado para publicação 02.03 .93

Aprovado para publicação em 03.05 .93 